\title{
DIAGNOSIS OF LEFT VENTRICULAR HYPERTROPHY WITH ELECTRO- CARDIOGRAPHY AND ECHOCARDIOGRAPHY IN HYPERTENSION PATIENTS
}

\author{
Ratnesh N Gajbhiye ${ }^{1}$, Mangesh A Bankar *2.
}

${ }^{1}$ Associate Professor in Physiology, ANIIMS, Port Blair, India.

${ }^{* 2}$ Associate Professor in Pharmacology, ANIIMS, Port Blair, India.

\section{ABSTRACT}

Introduction: Electrocardiography (ECG) is relatively insensitive and cannot accurately quantitative the severity of left ventricular hypertrophy (LVH). Echocardiography has revolutionized the diagnosis of LVH because echocardiographic evidence of LVH occurs in 30 to 40 percent of hypertensive patients whose ECG and chest Xray are normal. Keeping in view the importance of detecting $\mathrm{LVH}$ in cases of hypertension, this study is conducted to see the correlation of electrocardiographic diagnosis of LVH with echocardiography among the local population in cases of hypertension.

Materials and Methods: About 30 males and females of age 38 - 74 years, having longstanding hypertension, where LVH is suspected were included in the study and ECG and echocardiography was done on the same day. Results: 22 (73.34\%) were found to have LVH on echocardiography. 16 (53.34\%) were found LVH on Electrocardiographically out of 30 patients. 22 (73.34) were in stage II hypertension and patients in stage I were 8 (26.67\%). 2 (25\%) had LVH on ECG alone and 4 (50\%) had left ventricular hypertrophy on echocardiography alone. $7 / 16$ (43.75\%) patients had left ventricular hypertrophy on electrocardiography and 15/16 had left ventricular hypertrophy on echocardiography $(93.75 \%)(p<0.05)$. Only $7 / 16$ patients had LV H on both ECG and ECHO.

Conclusion: echocardiography is more sensitive and offers a greater precision for detecting left ventricular hypertrophy especially when interventricular septum and posterior wall thickness measurements are taken into account. To make the left ventricular hypertrophy more specific on echocardiography, the left ventricular mass measurement is a better diagnostic tool.

KEY WORDS: Echocardiography, Electrocardiography (ECG), Left ventricular hypertrophy (LVH) and hypertension.

Address for correspondence: Dr. Mangesh A Bankar, Associate Professor in Pharmacology, ANIIMS, Port Blair, India. E-Mail: drmbankar@gmail.com

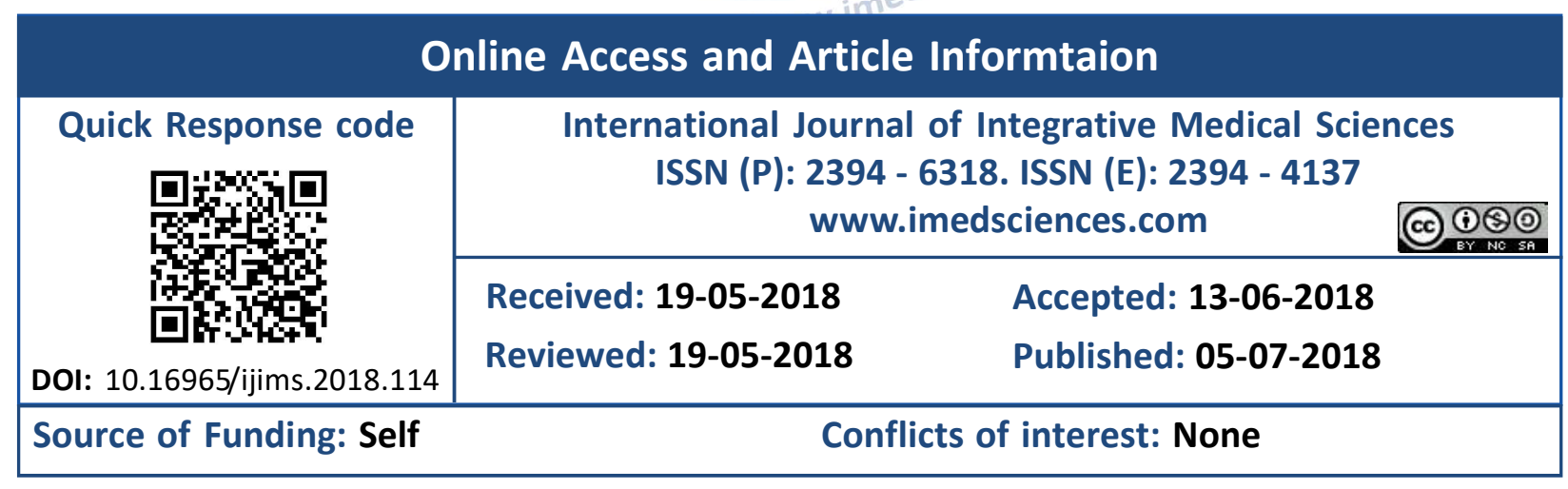

\section{BACKGROUND}

There is an increased risk of cardiac morbidity and mortality associated with left ventricular hypertrophy (LVH) in hypertension patients, so its detection is of major importance [1].

LVH is no longer considered an adaptive process that compensates for the pressure imposed on the heart and has been identified as an independent and significant risk factor for sudden death, acute myocardial infarction, and congestive heart failure [2]. The increase in left ventricular mass represents a common final pathway towards the adverse effects on the cardiovascular system and higher vulnerability to complications [3].

Electrocardiographic evidence of left ventricular hypertrophy is one of the most widely used 
markers of cardiovascular morbidity and mortality. It has become a clinical priority to precociously detect left ventricular hypertrophy by effective, low-cost screening, applicable to the population in general [4]. Electrocardiography (ECG) is relatively insensitive and cannot accurately quantitative the severity of LVH. Also LVH is difficult to diagnose by ECG if left bundle branch block is present. Because of these limitations, other diagnostic modalities have been used for LVH assessment [5]. The most successful and popular of these techniques has been echocardiography. Echocardiography has revolutionized the diagnosis of $\mathrm{LVH}$ because echocardiographic evidence of LVH occurs in 30 to 40 percent of hypertensive patients whose ECG and chest X-ray are normal [6]. Keeping in view the importance of detecting LVH in cases of hypertension, this study is conducted to see the correlation of electrocardiographic diagnosis of LVH with echocardiography among the local population in cases of hypertension.

\section{MATERIALS AND METHODS}

This Cross Sectional Study with 30 subjects of males (15) and females (15) of age $38-74$ years, mean age $56.14 \pm 8.79$ years S.D. having longstanding hypertension where LVH is suspected, Mitral and Aortic Regurgitation, Aortic Stenosis, and Coarctation of aorta,VSD were included in the study and Ischemic Heart disease, Bundle Branch Blocks was not included in the study. ECG and echocardiography was done on the same day. The blood pressure was recorded under basal conditions and patients were classified into various stages of hypertension according to the seventh report of joint national committee on detection evaluation and treatment of high blood pressure. The patients having systolic blood pressure $140-159 \mathrm{mmHg}$ and diastolic blood pressure $90-99 \mathrm{mmHg}$ were in stage I hypertension, while patients having systolic blood pressure [3] $160 \mathrm{mmHg}$ and diastolic blood pressure $100 \mathrm{mmHg}$ were labeled as stage II hypertension (JNCVII). The criteria for LVH in ECG were that proposed by sokolow and lyon 5 of [SV1+RV6] or [SV1 + RV6] $35 \mathrm{mmHg}$. The cases having LBBB were excluded from the study. On echocardiography following criteria was adopted (shubc, klein.AL) 6 Male: Interventricular septum thickness (IVS) $12.6 \mathrm{~mm}$
Posterior wall thickness $(\mathrm{pw})^{3} 11.9 \mathrm{~mm}$ Echocardiography machine used was Toshiba model $\mathrm{SSH}-140 \mathrm{~A}, 3.7 \mathrm{MHz}$ and $2.5 \mathrm{MHz}$ probe phased array, sector probes with 90 degree sector arc.

\section{RESULTS}

A total of 30 patients were studied. Equal no of patients i.e. male to female ratio 15:15 (50\% : $50 \%$ ) age range was between $38-74$ years with a mean $\pm S D$ age of $56.14 \pm 8.79$.

$22(73.34 \%)$ were found to have left ventricular hypertrophy (LVH) and 8 (26.67\%) were negative for left ventricular hypertrophy on echocardiography and electrocardiographically number of patients with left ventricular hypertrophy was 16 (53.34\%) and without left ventricular hypertrophy 14 (46.67\%) out of 30 patients.

Most of the patients i.e. 22 (73.34) were in stage 11 hypertension and patients in stage I were 8 (26.67\%). 2 (25\%) had LVH on ECG alone and 4 (50\%) had left ventricular hypertrophy on echocardiography alone. Among stage I hypertensions 14 were negative for left ventricular hypertrophy both on ECG and ECHO.

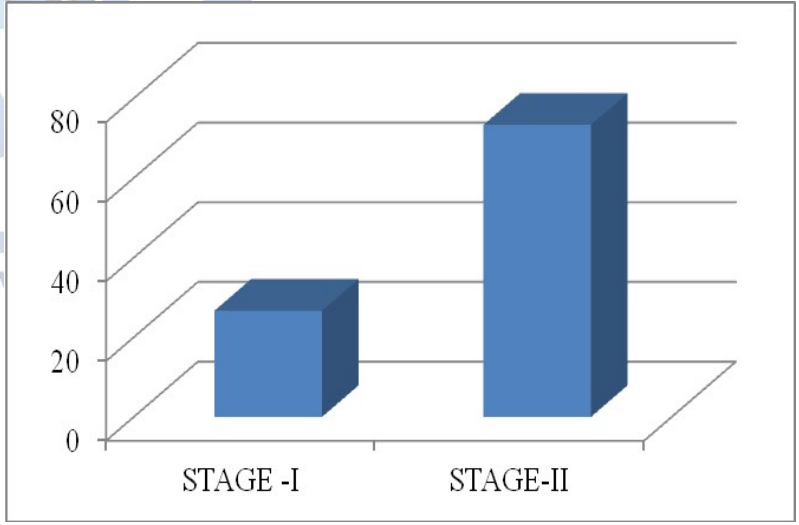

$16 / 30$ patients were found to have stage II hypertension. $7 / 16$ (43.75\%) patients had left ventricular hypertrophy on electrocardiography and 15/16 had left ventricular hypertrophy on echocardiography (93.75\%) $(p<0.05)$. Only $7 / 16$ patients had LV H on both ECG and ECHO.

Table 1: Showing number of patients positive with Electrocardiography, Echo Cardiography.

\begin{tabular}{|c|c|c|c|c|}
\hline \multirow{2}{*}{} & \multicolumn{2}{|c|}{ STAGE -I } & \multicolumn{2}{c|}{ SAGE-II } \\
\cline { 2 - 5 } & NO & $\%$ & NO & $\%$ \\
\hline ELECTROCARDIOGRAPHY & 2 & 25 & 7 & 43.75 \\
\hline ECHO CARDIOGRAPHY & 4 & 50 & 15 & 93.75 \\
\hline BOTH & 0 & 0 & 7 & 43.75 \\
\hline
\end{tabular}




\section{DISCUSSION}

Left ventricular hypertrophy is the marker of severity of hypertension, as an indication of target organ damage, and has it's implication on the course of disease in terms of morbidity and mortality [7]. It is also a better predictor of relapse of hypertension after drugs have been stopped [8]. The overall prevalence of left ventricular hypertrophy in adult population is between $10-15 \%$, it steadily increases with age and $10 \%$ above the age of 65 years has Left ventricular hypertrophy. It is 10 times commoner in hypertensive and obese subjects [9]. In the present study, the ECG criteria has shown a good specificity for left ventricular hypertrophy, particularly when strain pattern was seen, but is very insensitive [10]. As shown in the results, the $\mathrm{M}$ mode / 2D echocardiography has shown a greater precision and sensitivity in detecting left ventricular hypertrophy in long standing hypertension especially when ECG was negative for left ventricular hypertrophy. The only disadvantage of echocardiography is that it is a time consuming procedure. The higher prevalence of left ventricular hypertrophy in this study is because of selection of population, since all of the subjects were known hypertensives, with long standing history, poorly controlled blood pressures and poor compliance to regimens. Majority of the female population were above the age of 50 years and were in post menopausal period. Most of them were obese. In terms of sensitivity and specificity of echocardiography for left ventricular hypertrophy and in order to obtain critical results in terms of reproducibility, the left ventricular mass measurement would be more appropriate as it also involves left ventricular dimensions [11]. As $15-20 \%$ of patients in obese population are poorlyechogenic, the interventricular septum and posterior wall thickness echocardiography may sometimes give technical problems in measurements.

\section{CONCLUSION}

The electrocardiographic criteria for the presence of left ventricular hypertrophy in the standard 12 lead ECG is still the most commonly applied investigation and is strongly suggestive of left ventricular hypertrophy. The $2 \mathrm{D} / \mathrm{M}$ mode echocardiography is more sensitive and offers a greater precision for detecting left ventricular hypertrophy especially when interventricular septum and posterior wall thickness measurements are taken into account. To make the left ventricular hypertrophy more specific on echocardiography, the left ventricular mass measurement is a better diagnostic tool.

\section{REFERENCES}

[1]. Richard E. Katholi and Daniel M. Couri. Left Ventricular Hypertrophy: Major Risk Factor in Patients with Hypertension: Update and Practical Clinical Applications. International Journal of Hypertension. 2011:10.

[2]. Venugopal K, Gadwalkar SR, Ramamurthy P. Electrocardiogram and echocardiographic study of left ventricular hypertrophy in patients with essential hypertension in a teaching medical college. J Sci Soc. 2016;43:75-9.

[3]. Gurpreet Singh, Anand Gopal Singh Bawa, Savita Kapila, Amarjit Kaur, Saruchi Garg. Comparison of electrocardiographic criterias for LVH using Echocardiography as standard. International Journal of Contemporary Medical Research 2017;4(2):497500.

[4]. Casiglia E, Schiavon L, Tikhonoff V, Bascelli A, Martini B, Mazza A, et al. Electrocardiographic criteria of left ventricular hypertrophy in general population. Eur J Epidemiol. 2008;1-11.

[5]. Klein RC, Vera Z, DeMaria AN, Mason DT. Electro cardio graphic diagnosis of left ventricular hypertrophy in the presence of left bundle branch block. Am Heart J.1984 Sep;108(3 Pt 1):502-6.

[6]. M Razzak Mia, A R M Saifuddin Ekram, M Azizul Haque, Raisuddin. A Comparative Study of Electrocardiographic and Echocardiographic Evidence of Left ventricular Hypertrophy. TAJ 2007; 20(1): 24-7.

[7]. George A. Mensah. Hypertension and Target Organ Damage: Don't Believe Everything You Think!. Ethn Dis. 2016;26(3): 275-8.

[8]. Veronika van der Wardt, Jennifer K. Harrison, Tomas Welsh, Simon Conroy, John Gladman. Withdrawal of antihypertensive medication: a systematic review. J Hypertens. 2017; 35(9): 1742-9.

[9]. Mayo Clin Proc 1994;69:205-211. Gottdiener JS, Reda DJ, Materson BJ, et al. Importance of obesity, race and age to the cardiac structural and functional effects of hypertension. The department of Veterans Affairs Cooperative Study Group on Antihypertensive agents.J Am Coll Cardiol. 1994;24:1492-8.

[10]. Carr AA, Prisant LM, Watkins LO. Detection of hypertensive left ventricular hypertrophy Hypertension1985;7:948-954.

[11]. Devereux RB, Pini R, Aurigemma GP, Roman MJ. Measurement of left ventricular mass: methodology and expertise. J Hypertens. 1997;15:801-9.

How to cite this article: Ratnesh N Gajbhiye, Mangesh A Bankar. DIAGNOSIS OF LEFT VENTRICULAR HYPERTROPHY WITH ELECTROCARDIOGRAPHY AND ECHOCARDIOGRAPHY IN HYPERTENSION PATIENTS. Int J Intg Med Sci 2018;5(6):641-643. DOI: 10.16965/ijims.2018.114 